\title{
Fostering Diaologue for a Common Future: Asia-Europe Policy Forum (AEPF)
}

\author{
Wei Shen $^{1,2}$
}

Published online: 26 May 2020

(C) Springer-Verlag GmbH Germany, part of Springer Nature 2020

Asia-Europe Journal (AEJ) is very proud to present the inaugural edition of our new initiative-Asia-Europe Policy Forum (AEPF). It is a collection of policy briefs edited by our guest editor Professor Sven Biscop (Egmont Institute, Royal Institute for International Relations, Brussels, Belgium), and we hope you will find it stimulating, provocative and informative.

The Asia-Europe Policy Forum is aimed at providing timely analysis of important policy implications of current affairs in Asia-Europe relations and interactions or recent scientific results with strong implications on both regions. We would like to invite articles that are concise policy briefs of no more than 2000 words. The main criteria for inclusion for the Forum are impact, timeliness and novelty of the articles and their significance in providing needed and fresh insight on a topic pertinent to policymakers, academic communities and the general public in Asia, Europe and beyond. The opinions and debates for the Forum should follow a logical flow and be convincingly supported by reliable statistical data, policy documents and appropriate references, and organised in the format of a collection of original and interlinking synthesises.

In concordance with AEJ's mission, AEPF topics are usually chosen by the Editorin-Chief/Forum Editor who then selects potential guest editors and/or contributors. AEJ also welcomes and occasionally calls for contribution for spontaneous propositions from academic and policy community on a timely topic. Such proposals should be discussed with the Editor in the first place. Each Forum will be organised by a guest editor (co-editors or in conjunction with the Forum Editor), who has the primary

Professor Wei Shen is the Editor-in-Chief of Asia-Europe Journal and founding editor for the Policy Forum. Professor Shen is the Associate Pro Vice-Chancellor (International Relations) at Deakin University, Australia, and holder of Jean Monnet Chair in EU-China Relations at the EU*Asia Institute of ESSCA School of Management, France. He is also Vice-President at EU-Asia Centre and Non-Resident Senior Fellow of Centre for China and Globalization (CCG).

Wei Shen

wei.shen@deakin.edu.au

1 Deakin University, Victoria, Australia

2 EU-Asia Institute, ESSCA School of Management, Angers, France 
responsibility for refereeing contributions to the Policy Forum. Based on the final submission of the manuscript, the final decision is taken by the Editor-in-Chief.

The introduction of AEPF coincides with a significant moment for the shifting of global order and the interregional relations between Asia and Europe. We hope the AEPF will address the gap between academic research and policy formulation while fostering progressive dialogue and collaboration across disciplinary boundaries and stakeholder communities. It is our wish that the debates within the Policy Forum will advance our understanding and conversations on the challenges and opportunities of a common future for Asia and Europe through an interdisciplinary scholarship in social sciences that has been the cornerstone of our Journal.

Therefore, it gives me immense pleasure to introduce you to the AEPF with the inaugural issue focusing on the outbreak of the Covid-19 pandemic, which has already affected countries all over the world, endangering citizens' the lives and well-being and menacing the world economy. The contributions from senior diplomats and leading scholars examine the ripple effects of the pandemic, the effectiveness of short-term responses by governments in Asia and Europe, also with an outlook to the long-term scenarios of adapting to the new environment in a post-Covid-19 world. I feel very grateful to have our guest editor Professor Sven Biscop working with me in putting this inaugural issue together in a relatively short time and I would like to thank all of the contributors for delivering their rigorous analysis so promptly.

I sincerely hope you will enjoy reading the Policy Forum and look forward to hearing your feedbacks on this new initiative and, more importantly, to receiving your contributions to our debates in the very new future. 